\title{
Is Preventive Detention Morally Worse than Quarantine? $^{1}$
}

\author{
Thomas Douglas
}

[This is a pre-publication version. The final version has been published in Jan W. de Keijser, Julian V. Roberts, and Jesper Ryberg (eds.) Predictive Sentencing: Normative and Empirical Perspectives (London: Hart Publishing).]

\section{Introduction}

In some jurisdictions, the institutions of criminal justice may subject individuals who have committed crimes to preventive detention. By this, I mean detention of criminal offenders (i) who have already been punished to (or beyond) the point that no further punishment can be justified on general deterrent, retributive, restitutory, communicative or other backwardlooking grounds, (ii) for preventive purposes - that is, for the purposes of preventing the detained individual from engaging in further criminal or otherwise socially costly conduct.

Preventive detention, thus understood, shares many features with the quarantine measures sometimes employed in the context of infectious disease control. ${ }^{2}$ Both interventions involve imposing (usually severe) constraints on freedom of movement and association. Both interventions are standardly undeserved: in quarantine, the detained individual deserves no detention (or so I will, for the moment, assume), and in preventive detention, the individual has already endured any detention that can be justified by reference to desert. Both interventions are, in contrast to civil commitment under mental health legislation, normally imposed on more-or-less fully autonomous individuals. And both interventions are intended to reduce the risk that the constrained individual poses to the public.

Yet despite these similarities, preventive detention and quarantine have received rather different moral report cards. Preventive detention, and the assessments of forensic risk that it necessitates, have been subject to frequent and diverse moral objections (eg, Corrado 1996a: 778; Duff 2007; Kitai-Sangero 2009; Morse 2011; Harcourt 2012). By contrast, quarantine is relatively well accepted by those who might be thought most likely to offer moral critique of it: scholars of public health ethics and public health law. It also appears to be accepted by many of the very same scholars who object to preventive detention. Despite the obvious parallels between preventive detention and quarantine, these scholars have typically remained silent on quarantine. ${ }^{3}$ Indeed, when theorists of criminal justice have mentioned quarantine, they have often done so precisely because it seems to them to be morally justified. For

\footnotetext{
${ }^{1}$ I would like to thank Jesper Ryberg and audiences in Oxford and Utrecht for comments on an earlier version of this paper. I thank Areti Theofilopoulou for her research assistance.

${ }^{2}$ I use the term quarantine to refer to what would more properly be called 'isolation or quarantine'. 'Isolation' standardly refers to the separation from others of individuals infected with an infectious agent, while 'quarantine' refers to the separation of individuals merely at risk of being infected. I use the term 'quarantine' to refer to both.

${ }^{3}$ For exceptions, see Meyerson (2009: 510); Ashworth and Zedner (this volume).
} 
example, Derek Pereboom and Gregg Caruso seek to defend preventive detention in part by drawing parallels between it and quarantine (Pereboom 2014: 156-74; Caruso 2016). ${ }^{4}$

Why the comparative critical silence on quarantine, as compared to preventive detention? Several candidate explanations are available. It could be, for example, that moral objections to quarantine are comparatively rare because most potential commentators regard it as so morally problematic as not to be worth discussing; because quarantine itself is rare (Meyerson 2009: 510); or because the ethical analysis of quarantine has fallen down the disciplinary cracks between healthcare ethics and political philosophy. However, it is plausible that at least part of the explanation lies in widespread implicit acceptance that there is a genuine moral difference between these practices - that preventive detention is more morally problematic than quarantine. ${ }^{5}$ A soft version of this view would hold that

Soft Moral Difference: preventive detention is typically in at least one respect more morally problematic than quarantine.

A harder version of the view would posit a universal moral difference between the two practices:

Hard Moral Difference: preventive detention is always in at least one respect more morally problematic than quarantine.

I believe that both of these views warrant attention. Unfortunately, though, as a philosopher, I am not well qualified to assess the former. Whether preventive detention is typically more problematic than quarantine will depend heavily on the facts about how these two practices are typically imposed and what effects they normally have, on those subject to them, on those whom they are intended to protect, and on those required to fund them. These are empirical questions that cannot be addressed through philosophical methods. I thus focus here purely on the latter view.

The primary purpose of this chapter is to challenge Hard Moral Difference. I seek to advance this challenge by considering and rejecting six attempts to justify it, beginning with four attempts that I think can be easily dismissed, and proceeding to consider in more detail two attempts that are more resilient to criticism. Ultimately, I argue that all six attempts fail: preventive detention is not always more problematic, in one respect, than quarantine - at least, not if my survey is exhaustive and my arguments are persuasive. I conclude by drawing out some implications of my argument.

Of course, it does not follow from my argument that preventive detention is not in some cases more problematic than quarantine. Perhaps it is even typically more problematic, as Soft Moral Difference asserts. A secondary purpose of this chapter, pursued in parallel to the first, is to identify the considerations that determine whether and when preventive detention is indeed in some respect more problematic.

\section{Preliminaries}

\footnotetext{
${ }^{4}$ For other discussions of preventive detention that also touch on quarantine, see Ashworth and Zedner (this volume); Slobogin (2011).

${ }^{5}$ This view has sometimes been explicitly or implicitly endorsed by critics of preventive detention (Gavaghan et al 2014: 82-3).
} 
Before beginning to pursue either of these purposes, however, I must offer two preliminary comments and introduce three significant assumptions.

The first preliminary comment concerns the relationship between preventive detention and risk-based sentencing, the topic of this volume. Preventive detention, as I have defined it, can occur after completion of a criminal sentence: offenders are transferred to preventive detention when or after their sentences expire. But preventive detention can also occur within the confines of a sentence (van Ginneken, this volume; Ashworth and Zedner, this volume).

Suppose an offender is sentenced to a period of 10 years in prison, with a minimum tariff of 5 years. Suppose that the initial 5 years of imprisonment are intended to realise general deterrent and/or backward-looking goals, with any further detention being subject to risk assessment and intended to prevent the individual from further offending. Finally, suppose that 5 years is indeed the maximum period of detention that can be justified on nonpreventive grounds. In this case, if the offender is detained beyond five years, the portion of detention that extends beyond the five-year mark will qualify as preventive detention, as I have defined it. We will thus have an instance of within sentence preventive detention. In such cases, the preventive element of the sentence will normally (and, I would say, should) be made contingent on a risk-assessment, or series of risk-assessments, and we will thus have an instance of risk-based sentencing.

Thus, preventive detention can, but need not, be an upshot of risk-based sentencing. ${ }^{6}$ In the remainder of this chapter, I focus on preventive detention rather than risk-based sentencing, since I believe the issues I raise apply also to post-sentence preventive detention. However, everything I will say applies a fortiori to risk-based sentencing.

The second preliminary comment is a note about what I will not cover. I will not have anything to say about objections to preventive detention that, I think, clearly apply equally to quarantine. In this category are objections appealing to a Kantian requirement never to treat individuals merely as means (Husak, this volume), and objections to treating some individuals less favourably than others on the basis of statistical generalisations about groups (Meyerson 2009: 514-15).

Now for the three assumptions. I assume, first, that we are comparing only forms of preventive detention and quarantine that are actually used, or are likely to be used in the future. I take it that the proponent of Hard Moral Difference is making a claim about these actual or likely practices, not about hypothetical, ideal versions of them. Thus, it is compatible with Hard Moral Difference that some idealised forms of preventive detention would be in no way more morally problematic than quarantine.

Second, I assume throughout that preventive detention is imposed by the institutions of criminal justice under the provisions of criminal law, and that quarantine is imposed by public health authorities under the provisions of public health law. ${ }^{7}$ This allows me to exclude from both categories, and thus set aside, some rather institutionally messy and ethically complex detention practices, including the civil commitment of psychiatric patients deemed to pose a risk to self or others (see, for discussion of these, Slobogin 2011).

Finally, third, I grant the proponent of Hard Moral Difference that those subjected to preventive detention are no more liable to the harms and intrusions that it involves than are those subjected to quarantine. Though preventively detained individuals do not positively deserve their detention, it could be held that they have, in committing a crime, made

\footnotetext{
${ }^{6}$ That preventive detention can occur either within or outside a criminal sentence is not an idiosyncratic implication of my way of understanding of preventive detention. See also Slobogin (2011: 1128-9, 1140).

${ }^{7}$ This stipulation precludes quarantine from qualifying as a kind of preventive detention. For a contrasting view, see Slobogin (2011).
} 
themselves (more) liable to it; they have forfeited some of the rights that would ordinarily be infringed by such detention, or caused those rights to lose some of their normal force or scope. By contrast, it might be held that those subjected to quarantine retain all of their normal rights, with their normal force and normal scope. These views could be used to diffuse some arguments for Hard Moral Difference; for instance, some might hold that, even if preventive detention seems to involve some rights infringement that quarantine does not, this turns out to not to be so, since criminal offenders have in fact forfeited the rights in question. I exclude this possibility by assuming that preventively detained individuals are no more liable to the constraints they face than are quarantined individuals; both groups possess the same relevant rights, and those rights have the same force and the same scope.

With these assumptions in hand, let me turn to the task of assessing Hard Moral Difference.

\section{Four Preliminary Arguments}

I begin by assessing four arguments for Hard Moral Difference that can, I think, be dismissed easily, and in similar ways.

The first of these arguments holds that preventive detention is more morally problematic than quarantine in the respect that the expected benefits of preventive detention, in the form of public protection, are smaller than those of quarantine, so, other things being equal, less likely to outweigh the moral costs. The underlying thought here is that those with the sorts of infectious diseases that trigger quarantine procedures pose a greater risk to the public than those subjected to preventive detention (Smilansky 2017: 597-8).

The second argument adverts to the putatively self-fulfilling nature of the riskassessments necessitated by preventive detention. It has been argued that, when individuals are deemed to be high risk in the context of criminal justice, this judgment, and the interventions that follow from it, in fact increase the risk that the individual will re-offend (Sidhu 2015). It might be argued that this effect does not occur, or at least is weaker, in the context of infectious disease control. After all, the mechanism via which criminal justice risk assessments become self-fulfilling is often supposed to be partly psychological: those deemed to be high risk come to see themselves as such, and this makes them less psychologically resilient to crime-promoting environments. It may seem doubtful that any such process could occur in the case of infectious disease.

A third argument holds that the declarations of high forensic risk necessitated by preventive detention are more stigmatising than the declarations of high infectious risk necessitated by quarantine. Individuals deemed to be high risk in the context of criminal justice may not only be subjected to longer periods of detention than their 'low risk' contemporaries, they may also become the object of significant social disapproval, which may be intrinsically harmful and lead to myriad other forms of disadvantage (von Hirsch 1972: 743; Silver and Miller 2002). It might be argued that this effect does not occur, or at least is weaker, when individuals are deemed to be 'high risk' in the context of infectious disease control.

Finally, the fourth argument holds that the risk assessments necessitated by preventive detention are more inegalitarian than those necessitated by quarantine. Risk assessments will tend to exacerbate social inequality when (i) those deemed high risk are on average more disadvantaged than others (on whatever metric is relevant to the moral assessment of social equality), and (ii) the assessments, or interventions that follow from them, tend to increase that disadvantage (Sidhu 2015; Gavaghan et al 2014: 25). It can plausibly be argued that both (i) and (ii) hold in relation to assessments of forensic risk: disadvantaged groups are 
overrepresented among those deemed to be high risk by commonly used forensic risk assessment tools, and it is plausible that both the longer periods of incarceration and the stigmatisation endured by these individuals tend to increase levels of disadvantage (HannahMoffat and Struthers Montford, this volume). It might be argued that the risk assessments employed in infectious disease control are less strongly associated with prior disadvantage, and less liable to produce further disadvantage (for example, because they are less stigmatising).

I believe that all of these arguments face the same problem: they do not apply universally. Thus, though they may support Soft Moral Difference, they do not support Hard Moral Difference; they do not show that preventive detention is always in one respect more problematic than quarantine. ${ }^{8}$ This is true even when we limit ourselves to actual and likely preventive detention and quarantine practices.

Consider first the claim that preventive detention has smaller benefits than risk-based quarantine. This may be true of many pairwise comparisons between the two kinds of intervention, but it is not true of all. Some prevailing forms of quarantine can be expected to have rather small benefits. Consider quarantine procedures that involve restraining individuals who live in an area where a pandemic is thriving, but who have had no close personal contact with infected individuals and whose individual risk of being infected thus remains low. The containment of any one individual in such cases has a very low expected benefit. There are also some prevailing forms of preventive detention that probably have large expected benefits. These may include the detention of those who have perpetrated major terrorist attacks and appear to be 'unreformed'. The detention of these individuals plausibly has greater expected benefits than many instances of quarantine.

Consider next the claim that preventive detention is more problematic than quarantine because forensic risk assessments are self-fulfilling in a way that infectious disease risk assessments are not. Again, this claim does not hold universally. Though forensic risk assessments can have a self-fulfilling effect, infectious disease risk assessments can also be self-fulfilling, for example, because individuals who are deemed to be at a high risk of being infected, but are in fact uninfected, are quarantined alongside individuals who are indeed infected. Such quarantine procedures can significantly increase one's risk of becoming infected.

Similar points can be made in relation to the claim that the declarations of high forensic risk necessitated by preventive detention are more stigmatising than the declarations of high infectious risk necessitated by quarantine. It is true that there is often a very strong negative stigma associated with criminality. However, there is also a strong negative stigma associated with some infectious diseases, with HIV being the most obvious example (Van Brakel 2006; Whittle et al 2017). It thus seems plausible that at least some declarations of high forensic risk are no more negatively stigmatising than some declarations of high infectious risk.

In response, it might be argued that the negative stigma associated with declarations of high forensic risk is different in kind from that associated with declarations of high infectious risk. The former typically has a moral character, whereas the latter typically does not. Those declared to pose a high forensic risk are not merely stigmatised as dangerous, like those deemed to pose a high infectious risk, they are also deemed to be morally flawed, perhaps in part because the imposition of preventive detention is itself sometimes mistakenly taken as an

\footnotetext{
${ }^{8}$ Though I do not have the space to argue it here, I think the same point holds in relation to three other reasons that might be given for thinking that preventive detention is more problematic than quarantine: the conditions of preventive detention are harsher than those of quarantine, forensic risk is more difficult to accurately predict than infectious risk, and preventive detention can more easily be replaced with less restrictive alternatives than can quarantine.
} 
official expression of moral condemnation rather than as a purely preventive measure. ${ }^{9}$ However, even this difference is not universal. Some infectious diseases are associated with heavily moralised behaviours such as illicit drug use and homosexual or unprotected sex, and these diseases frequently carry a stigma that is moral in nature. Quarantine measures may help to reinforce that stigma. Moreover, even if there is a difference in the kind of stigma associated with high forensic risk and high infectious risk, it does not clearly follow that preventive detention is always more problematic than quarantine. After all, it is plausible that stigma matters only insofar as it diminishes the wellbeing of the stigmatised individual, and even if forensic risk assessments produce a different - and perhaps more serious - kind of stigma than infectious risk assessments, it may be that the overall effect on wellbeing produced by these two different kinds of stigma is similar. Alternatively, it may be that, even if there is a greater stigma-related wellbeing-loss in the case of preventive detention than in quarantine, this is in some cases offset by countervailing effects on wellbeing (e.g., the greater risk of acquiring a disease associated with certain forms of quarantine).

Finally, the claim that forensic risk assessments are more inegalitarian than infectious disease risk assessments also does not hold universally. Because a person's being deemed to pose a high infectious risk can lead to both negative stigma and an increased risk of becoming infected, such assignments of risk can contribute substantially to disadvantage. Moreover, in some cases the assignment of high infectious disease risk can be expected to track pre-existing disadvantage, because acquisition of some infectious diseases is correlated with prior disadvantage. For example, within Europe alone, there is evidence that meningococcal meningitis and hepatitis A are associated with low socio-economic status (Twisselmann 2000; Hrivniaková et al 2009; Williams et al 2004), Methicillin-resistant Staphylococcus aureus infection is associated with social deprivation (Bagger et al 2004), and tuberculosis disproportionately afflicts persons from a range of frequently disadvantaged populations including immigrants, homeless people, substance abusers, prisoners, and HIV positive persons (Semenza and Giesecke 2008; Klinkenberg et al 2009; ECDC and WHO Europe 2013).

\section{Desert}

Let us turn to consider a more promising argument for Hard Moral Difference. This argument invokes a desert-based constraint on detention within the context of criminal justice.

Many object to preventive detention on the grounds that it flaunts the requirement that the institutions of criminal justice not impose more harm or intrusion than an individual deserves, or, as I take to be equivalent, that they not impose harm or intrusion that is disproportionately severe relative to the individual's culpability (Morse 2011; Gavaghan et al 2014: 75). (This is often called the 'negative retributivist constraint'.) By contrast, considerations of culpability and desert are seldom raised in discussions of the ethics of quarantine, and I am not aware of anyone having defended an analogue of the negative retributivist constraint in relation to quarantine and other public health practices. ${ }^{10}$ Perhaps,

\footnotetext{
${ }^{9}$ I thank Jesper Ryberg for pointing this out to me.

${ }^{10}$ Considerations of proportionality are sometimes raised in relation to public health (Childress et al 2002: 173). However, the concern here is not with proportionality to desert or culpability. The concern is not that public health interventions might impose more harm or intrusion than the targeted
} 
then, preventive detention is more morally problematic than quarantine in virtue of the undeserved harm or intrusions that it imposes.

An initial problem with this suggestion is that quarantine also imposes underserved harm and intrusions: I have been assuming throughout that individuals subjected to quarantine are not at all culpable, and that the harm and intrusions that they suffer are thus underserved. It seems clear that this assumption holds in at least some cases of quarantine. There may be cases in which quarantined individuals are culpable for the infectious risk that they pose; for example, they may have acquired the infectious condition through unsafe sexual practices or through violating the conditions of a previously imposed quarantine, or they may have negligently failed to take steps to have the infection treated. However, there are clearly also cases in which quarantined individuals are not at all culpable, and even in cases where they are culpable, it is in most cases not plausible that their culpability rises to the level that they deserve the severe constraints imposed by quarantine.

It might be argued, however, that the institutions of public health are not bound by the same desert-based moral constraints as those of criminal justice. That is, it might be argued that public health institutions fall under no analogue of the negative retributivist constraint. Thus, even if both preventive detention and quarantine impose undeserved harm and intrusions, this may violate a moral constraint in the case of preventive detention, but not in that of quarantine. The difference between them lies not in whether they impose underserved harm or intrusions, but in whether, in doing so, they violate a moral constraint.

The question then becomes: why think that institutions of public health are free from the sort of desert-based moral constraints that apply to institutions of criminal justice? Why not accept an analogue of the negative retributivist constraint in public health? After all, the negative retributivist constraint plausibly derives from a more general requirement that the state and its agents not impose more suffering on individuals than they deserve, and this more general requirement would apply also to the individuals and institutions responsible for quarantine.

An initial answer to these questions would appeal to the different goals of criminal justice and public health. Inflicting deserved harm or intrusions is part of the purpose of criminal justice, but not part of the purpose of public health. Perhaps this explains why desert-based constraints apply in criminal justice, but not in public health.

In the absence of further elucidation, this suggestion is unconvincing: it is not clear why desert-based constraints should be connected to desert-based purposes. After all, within penal theory, the two sometimes come apart: some accept the negative retributivist constraint while denying that punishment serves any desert-related purpose (Hart 1968: ch. 1). More importantly, the sorts of considerations typically mentioned in favour of the negative retributivist constraint do not presuppose a desert-based purpose of punishment. The chief motivation for accepting the constraint is that it is otherwise difficult to rule out the punishment of innocents and the imposition of harsh punishments on the perpetrators of minor wrongs (McCloskey 1972: 127; Pereboom 2014: 164). These concerns are consistent with non-desert-based accounts of the purposes of punishment, and indeed are frequently illustrated by reference to 'scapegoating' punishments administered for a forward-looking, general deterrent purpose. If the justification of desert-based constraints within criminal justice is independent of the purposes of criminal justice, it is unclear why the justification for desert-based constraints in public health should be undermined by the fact that public health has no desert-based purpose.

individuals deserve, but that they might impose more harm or intrusion than can be justified by the objective threat that the targeted individuals pose. 
However, perhaps there are other grounds for thinking that desert-based constraints apply in criminal justice, but not in public health. It might be argued that there are reasons, pertaining to the costs of assessing individual desert, for adopting different desert-based constraints in the two domains. Individual desert is difficult to assess, and the institutions of public health are not well set-up to conduct such assessments. It may be that the costs of reforming public health institutions to accurately assess desert would outweigh the benefits, and it may be that any attempt to assess individual desert without such reforms would be unacceptably prone to errors. The institutions of criminal justice are, however, arguably far better placed to assess desert. For instance, they include trial-based procedures for identifying and appraising the intentions of individual criminal offenders. Perhaps, then, the costs of accurately assessing desert are acceptable in the context of criminal justice, but unacceptable in the context of public health. And perhaps it follows that public health institutions are free from any desert-based constraints, though the institutions of criminal justice are not.

This argument is unpersuasive. It assumes that, if assessing desert would be unacceptably costly for some institutions, then those institutions fall under no desert-based constraints. In effect, they are free to ignore considerations of desert. But this is implausible. More plausible is that, if assessing individual desert is too costly for some institutions, those institutions should still seek to avoid inflicting underserved harm or intrusions, though they should rely on reasonable assumptions about who deserves what, rather than individualised assessments of desert. (In the case of the public health institutions that administer quarantine, the most reasonable assumption to make would surely be that all individuals subjected to quarantine do not deserve the harms and intrusions that this entails, since, for almost all quarantined individuals, this will be true.)

Another argument for rejecting a desert-based constraint within public health would appeal to the idea of an efficient division of moral labour. This is the idea that in some cases different moral obligations and permissions should be assigned to different agents because this heterogenous distribution of moral considerations more efficiently realises some moral objective than would a uniform distribution. Rawls famously held that social justice is best achieved by adopting stringent requirements of justice in relation to the design of a society's basic institutions, while individuals acting within this institutional structure are for the most part left free to set aside justice and pursue their own good (Rawls 1993: 268-9; Nagel 1995; Murphy 1999; Scheffler 2005). Similarly, it has been suggested that the goal of sociallybeneficial scientific progress is best realised by ascribing to scientists an obligation only to pursue their curiosity, while science regulators and funders ought to nudge the direction of science towards social benefit and away from social harm. ${ }^{11}$

In the present context, it might be argued that the goal of matching suffering to desert is most efficiently realised by leaving this task to the institutions of criminal justice, while other institutions - including those of public health - are left free to ignore considerations of desert.

The difficulty, however, is that the institutions of criminal justice seem woefully inadequate for the task of ensuring, in general, that people suffer no more or less than they deserve. One reason for this is that they correct for the effects of other institutions only in one direction; though they may sometimes impose deserved suffering when other institutions have failed to do so, they do nothing to negate or compensate for the imposition of undeserved suffering by other parties or institutions. For instance, they do nothing to correct for the imposition of undeserved suffering through quarantine. It is thus difficult to see how one could plausibly claim that institutions of public health may permissibly ignore considerations of desert on the basis that the institutions of criminal justice will efficiently

${ }^{11}$ See, for discussion of this view, Douglas (2014). 
negate or compensate for any underserved suffering that they might impose. Moreover, it is doubtful that any other institutions $d o$ efficiently negate or compensate such undeserved suffering. It is thus difficult to see how an appeal to an efficient division of moral labour could get the institutions of public health 'off the hook' with respect to desert.

\section{Respect}

A sixth argument for Hard Moral Difference holds that preventive detention violates a requirement to treat people with respect, whereas quarantine does not. ${ }^{12}$

The risk that individuals subjected to preventive detention pose to the public is a risk that arises from their own rational agency: the risk is that they will choose to exercise their rational agency in harmful ways. It might be thought that, in cases where an individual poses such a risk, one must seek to mitigate the risk through engaging the rational capacities of those individuals, for example, through engaging them in forms of 'talking therapy' that help them to appreciate their reasons to refrain from harmful conduct. Yet preventive detention does not seek to engage rational capacities. It thus arguably fails to respect the detained individuals' by treating them as if they were not rational agents - as if, in Von Hirsch's terms, they were 'beasts in a circus....beings that must be restrained, intimidated, or conditioned into submission because they are incapable of understanding that harmful conduct is wrong' (Von Hirsch 1992: 67).

Of course, quarantine also does not engage the rational capacities of the detained individual, but in this case, it might seem that there is no failure of respect, since the risk that the individual poses is in any case not a rationality-based risk: it is not that we fear that the (possibly) infected individual might choose to exercise her rational agency in ways that cause harm to the public. ${ }^{13}$ True, quarantine treats the risky individual as if she were simply a dangerous 'beast', but, with regard to her infectiousness, she is like a dangerous beast, so perhaps there is nothing disrespectful about failing to engage rational capacities in this case. ${ }^{14}$

${ }^{12}$ See, for the claim that preventive detention fails to respect agency, Smilansky (1994; 52-3); Corrado (1996a; 779); Duff (2007: 165); Morse (2011) For similar objections to other criminal justice practices, see Zedner (2010: 25) and Hoskins (2013).

${ }^{13}$ In some cases, rational agency does play a role in mediating the infectious risk that the quarantined individual poses to others. It may be, for example, that the individual will infect others only if he chooses to engage in unsafe sexual practices or fails to respect voluntary constraints on free movement. Still, it seems plausible that rational agency plays a more central role in generating forensic risks than it does in generating infectious ones, and perhaps this is all the present argument requires.

${ }^{14}$ Denise Meyerson's (2009: 527-8) statement of this argument is the most complete I have been able to find. She holds that "Some predictions of dangerousness are not inconsistent with respect for a person's autonomy. As Barbara D Underwood points out, when 'the predicted fact is not subject to individual control, then predicting that fact is less threatening to the value of respect for autonomy. For example, prediction of violent behavior by the mentally ill ... is seldom characterized as a threat to the autonomy of the mentally ill.' The same could be said about isolating someone who has a highly infectious disease, since spreading the disease is not under their control. It is very different, however, when someone is deprived of their liberty when the threat they pose is under their control. In cases such as this, preventive measures assume that people who are capable of choosing not to cause harm will cause harm, thereby denying them the opportunity to choose differently. They are treated as 'predictable objects', or 'dangerous animals', rather than as individuals with the capacity for free choice." The argument entertained by Meyerson here differs from the one I am considering only in 
One worry about this argument relates to the suggestion that we need not engage a person's rational capacities in seeking to mitigate their infectious risk, since that risk does not arise from the quarantined individual's rational agency. We might wonder why the source of a risk should matter for how we should seek to mitigate it. An alternative view would hold that, whenever a risk can be mitigated through means that engage rational capacities, then it ought to be so mitigated, regardless of its source. What matters, for respect, is not whether a risk arises from rational agency, but whether it can be effectively mitigated through means that engage it.

I will not pursue this worry; I will take it as given that quarantine involves no failure of respect. Instead, I focus my attention on the other half of the present argument for Hard Moral Difference: the claim that preventive detention always fails to respect the detained individual. To assess this claim, we need to get clearer about what, exactly, respect requires. In what follows, I will try to show that it is difficult to formulate this requirement in such a way that it is strong enough to rule out all cases of preventive detention, but weak enough to avoid implying that seemingly innocuous forms of treatment are disrespectful.

One understanding of the respect requirement is suggested by the claim-alluded to above - that failing to engage an individual's agency involves treating her as if she were a non-agent. On a straightforward interpretation, the thought here is that, for $A$ to respect $B, A$ 's actual treatment of $B$ must differ from the treatment that $A$ would have given to $B$ had $B$ not been a rational agent. $B$ 's rational agency must have made a difference to how $A$ treated her.

The problem with this formulation is that it leaves the respect requirement demanding far too much. We often treat people in ways no different from how we would also have treated comparable non-rational animals, and in many cases, this seems morally innocuous. Consider the installation of centre barriers intended to prevent head-on collisions on highways. This seems to treat drivers precisely as we might treat equivalently dangerous nonrational animals, yet it does not seem disrespectful.

To avoid this problem, one might hold that, in determining whether $A$ respects $B$, we should look not at individual forms of treatment that $A$ gives to $B$, but at $A$ 's treatment of $B$ considered globally. (Perhaps we should also consider how $A$ would have treated $B$ in certain counter-factual circumstances.) Suppose the state installs centre barriers on highways, but also employs rationality-engaging measures to prevent head on collisions: for example, it also presents drivers with reasons to take frequent breaks to avoid sleepiness. In that case it might seem that, considered globally, the state is treating drivers differently from how it would treat non-rational animals, so the respect requirement is satisfied.

However, if we take this more global perspective, then it is not clear why preventive detention must involve any failure of respect. To avoid such a failure, it would, on the present understanding, be enough to combine preventive detention with other, rationality-engaging interventions, as is often done.

Let us turn, then, to consider two further interpretations of the respect requirement. On the first of these interpretations, the requirement demands that $A$ not express a (certain kind of) objectionable negative appraisal of $B$-it is a requirement not to send the wrong kind of message. On the second interpretation, it demands that $A$ not act on the basis of a (certain kind of) objectionable negative judgment about $B$-it is a requirement not to act on the wrong kind of judgment. On the first of these two understandings, what matters is the meaning expressed ('message sent') by the putatively disrespectful treatment (call this the

invoking the narrower 'respect for autonomy' rather than my preferred, more generic 'respect', notfurther-specified. 
'expressivist' interpretation); on the second, what matters is the set of judgments that played a part in motivating it (call this the 'motivationist' interpretation).

These two understandings of the respect requirement are closely related, since the message sent by, for example, preventively detaining an individual plausibly depends on the judgments that played a part in motivating the imposition of that detention. However, the meaning expressed by preventive detention could also depend on other factors, such as mere social conventions regarding what different actions mean, so it is possible that the expressivist and motivationist interpretations could come apart. In what follows, I will take the motivationist interpretation as my target, though, as it happens, I believe that everything I will say about the motivationist interpretation of the respect requirement applies to the expressivist interpretation as well.

On the motivationist interpretation of the respect requirement, whether preventive detention is disrespectful depends on whether there is some objectionable moral judgment that always plays a role in motivating the imposition of preventive detention. What might that judgment be?

Here's an initial suggestion: the objectionable judgment is the judgment that the detained individual is not a rational agent. On this view, the disrespectfulness of preventive detention derives from an underlying failure, on the part of the detaining agents, ${ }^{15}$ to recognise the rational agency of the detained individual.

This suggestion faces an obvious problem as a basis for Hard Moral Difference: there is no reason to suppose that the agents responsible for imposing preventive detention must make any such judgment. Indeed, in cases where the detaining agents couple preventive detention with rationality-engaging interventions, such as talking therapies, we have clear reason not to impute any such judgment; in such cases, the detaining agents clearly take the detained individual to be a rational agent. Suppose that Arama, who is deemed to pose a risk of criminal offending, is subjected to a package of interventions which include a short period of preventive detention, but also rationality-engaging interventions, such as talking therapies, which extend over a longer period. The most credible explanation for why the detaining agents treat Arama in this way would be that they believe Arama to be a somewhat morally deficient rational agent; they believe her to be an agent who is somewhat capable of responding to moral reasons but who sometimes fails to do so, either because she is subject to non-rational forces, such as strong brute urges, or because she sometimes fails to recognise or chooses to ignore her moral reasons. The detaining agents thus employ a multifaceted risk reduction strategy that seeks both to engage Arama's rational agency, and to erect brute barriers to offending in case these appeals to her rationality fail.

Let us turn, then, to a more proposal that is more promising, as a basis for Hard Moral Difference, and is suggested by the case of Arama. Perhaps the objectionable judgment underpinning preventive detention is the judgment that the detained individual is a morally deficient rational agent, which I will gloss here as the judgment that the detained individual is less responsive to moral reasons than most.

Again, it might seem doubtful that the detaining agents always make such a judgment. It might seem that the detaining agents could deem that detainees are 'dangerous' or 'risky' without subjecting them to any moral appraisal, indeed, without thinking about morality at all.

\footnotetext{
${ }^{15}$ I use the term 'detaining agent' because I wish to remain silent on who, precisely, is responsible for imposing detention. Plausible candidates would include the state, the various institutions of criminal justice, and particular individuals within those institutions (such as judges, jurors and parole board members).
} 
However, perhaps it could be maintained that the detaining agents always, at least implicitly, endorse the judgment that detainees are morally deficient. After all, they plausibly believe that (i) the detainees are unusually dangerous, and that (ii) their dangerousness derives from the way in which they tend to exercise their rational agency. These propositions might seem to jointly entail that the detained individual is less responsive to moral reasons than most.

In fact, it is not clear to me that even such an implicit judgment can be attributed to the detaining agents. An individual might be subjected to preventive detention on the basis of the judgment that she is morally normal, though at high risk of recidivism due, say, to the especially challenging social circumstances that she faces. But let us concede, for the sake of argument, that preventive detention is invariably motivated in part by the judgment that the detained individual is morally deficient. The question then becomes: What's wrong with that? Why think that the respect requirement rules out acting on the basis of such a judgment?

One answer to this question would appeal to the epistemic status of the judgment. Acting on the judgment that a person is morally deficient may be disrespectful if and when that person is not in fact morally deficient, or not as deficient as one's judgment maintains, or when one's judgment has no good evidential basis. In such cases, we might say that one acts on an overestimation of the individual's moral failings. However, there seems little reason to suppose that imposing preventive detention will always be motivated in part by such an overestimation.

A second answer would hold that acting on the basis of a judgment of moral deficiency is disrespectful not because the judgment is false or epistemically unjustified, but because that judgment is at odds with moral equality. Perhaps respect requires that we treat one another as rough moral equals, in the sense of being roughly equally responsive to moral reasons, regardless whether this is in fact the case.

More would need to be said, however, about when it is disrespectful to act on the basis of a judgment that a person is morally deficient, for intuitively, we often act on the basis of such judgments without violating any moral requirement.

Consider criminal punishments - including detention - that are intended to realise backward-looking objectives, such as retribution, restitution, or the communication of social censure. Those who administer such punishments plausibly act on the basis of a judgmentimplicit or explicit - that the punished individual is (or at least, was) morally deficient. Yet many, including many opponents of preventive detention, accept backward-looking punishment as compatible with respect.

To avoid committing ourselves to the rejection of backward-looking punishment, we could distinguish between acting on the judgment that an individual has exhibited a moral deficiency in the past and acting on the judgment that she will exhibit moral deficiencies in the future. Perhaps respect requires only that we not act on predictions of moral failure-it requires us to take an optimistic stance regarding a person's future moral agency, but not to take a rosy view of their past moral agency.

However, even this view has implausible implications. Suppose that very rich individuals tend to commit more tax fraud than other individuals, partly because they normally have a strong prudential interest in evading taxation, partly because their wealth can often buy them good access to tax evasion strategies, and partly because they often became wealthy in part through an unscrupulousness that also disposes them to a willingness to evade taxes. For all of these reasons, very rich individuals tend to be less responsive to moral reasons than others when it comes to the payment of taxes. Suppose further that, being aware of this, the state focuses its anti-tax-evasion measures on very rich individuals. Some of these measures seek to engage the rational agency of the very rich-for example, through 
persuading them to pay their taxes_-but others merely seek to exclude certain available routes to tax evasion.

In this case, the agents who implement the anti-tax-evasion policy clearly act on the basis of a prediction of moral failure. Yet it is not clear that they disrespect the very rich.

Perhaps it could be said that this targeting of taxation enforcement efforts is consistent with respect because the underlying prediction is narrow in scope-those who implement the targeting predict that the very rich will be morally deficient only in a narrow domain, namely, with respect to tax evasion. Perhaps it is only acting on predictions of global moral failure that fall foul of the respect requirement.

However, if this is how we should understand the respect requirement, it is not clear that preventive detention always fails to meet it. Preventive detention may also be imposed on the basis of a predicted narrow moral failure. It might, for example, be imposed on the basis that an individual is deemed to be poorly responsive to moral reasons within the realm of sexual conduct.

Alternatively, we could hold that acting on the basis of predicted moral failure is disrespectful only when the prediction is based on factors for which the object of the prediction is not responsible (in such cases, we might aptly characterise the prediction as unfair). The predictions that underpin typical cases of preventive detention are often unfair in this sense. They are often based in part on demographic variables, such as age and sex, for which the detained individual is not responsible. By contrast, the prediction that is operant in the tax evasion case is based on a factor - being very rich - for which people generally are responsible. Perhaps this explains why there is not disrespect in the tax evasion case.

However, if our ultimate worry is with acting on the basis of unfair predictions of moral failure, then there is again no reason to suppose that preventive detention will always raise the worry. Whether it does will depend on the particular case. In some cases, preventive detention is grounded on factors such as past conduct or declared plans, for which the detained individual is responsible.

Finally, yet another suggestion would be that acting on the basis of a prediction of moral failure is disrespectful only when it also seriously harms or intrudes upon the person in whom the moral failure is predicted. Preventive detention plausibly involves serious harms and intrusions; anti-tax-evasion strategies may involve neither.

The problem with this suggestion, it seems to me, is that it is just not clear why the degree of harm or intrusion should be relevant to whether acting on the basis of a prediction of moral failure is disrespectful. The understanding of disrespect that $\mathrm{I}$ have been exploring is one in which disrespect arises from the judgments that motivate an action. Disrespectful treatment is disrespectful because of the motivations it manifests. It is not clear why, on this sort of view, the severity of the effects of the action should matter.

Perhaps there is some way of accommodating the intuition that the tax evasion case satisfies the respect requirement, despite the prediction of moral failure that it involves, without also generating the result that preventive detention also, at least in some cases, satisfies the requirement. However, I am at a loss as to how this might be done. I thus provisionally conclude that the appeal to the respect requirement, at least on the formulations of it that I have considered here, is unable establish Hard Moral Difference.

\section{Concluding Thoughts}

I have considered six arguments for Hard Moral Difference. I have argued that none succeed in sustaining that view, and have sought thereby to undermine, or at least diminish the credibility of, Hard Moral Difference. 
Still, several of the arguments that I have considered might, either independently or jointly, support a restricted version of Hard Moral Difference. For example, they might support Soft Moral Difference, according to which preventive detention is typically more problematic, in some respect, than quarantine. The interesting question then becomes: when is it more problematic, and in what respects, exactly? My discussion suggests a number of considerations that will be relevant here. First, there are those considerations surveyed briefly in the section 'Four Preliminary Arguments' above. Preventive detention may in some cases produce smaller social benefits than quarantine, or be more stigmatising, self-fulfilling, or inequality-promoting. Second, there are the factors discussed in in the section 'Respect'. In some cases, predictive detention may be disrespectful, in a way that quarantine is not, because it is based on an overestimation of the detainee's moral failings or on a prediction of moral failure that is unfair in the sense that it is based on factors for which the detained individual is not responsible.

What is the practical payoff of my discussion? Insofar as I have succeeded in clarifying the moral differences and similarities between preventive detention and quarantine, I hope that my discussion may point to ways in which the ethical assessment of preventive detention could be fruitfully informed by existing discussions of quarantine. With a few notable exceptions, discussions of the ethics of quarantine and the ethics of preventive detention have, so far as I can see, taken largely separate courses. My discussion suggests that there might be benefits of bringing them closer together.

More specifically, my arguments may, if successful, pose a substantive challenge to opponents of preventive detention, though showing as much is beyond the scope of this chapter. If I have succeeded in undermining Hard Moral Difference, this may support attempts to extrapolate arguments for quarantine into the sphere of criminal justice, so as to generate arguments in favour of preventive detention. But even if it turns out that Hard Moral Difference holds - for example because I have missed some argument that might be invoked in its defence - my discussion may put pressure on some particular arguments against preventive detention. For example, it may suggest that some desert-based arguments against preventive detention also count equally strongly against intuitively permissible forms of quarantine. This may present the proponents of these arguments with a dilemma: either drop the arguments, or accept a counter-intuitive position on quarantine.

My arguments may also suggest that conclusions regarding when and how quarantine ought to be imposed will carry over to preventive detention. For example, it would normally be thought that quarantine should be implemented in the least harmful and intrusive manner possible (Gostin 2001: 68), and that it should be coupled with treatments for medical conditions in virtue of which the individual poses a risk to the public (Slobogin 2011: 113940). Some would also hold that quarantined individuals should be compensated for the harms and restrictions imposed on them (Corrado 1996b: 3, 11; Schoeman 1981: 175, 181). My argument suggests that similar measures might be justified in the case of preventive detention. ${ }^{16}$ However my argument does not on its own establish this, for as I noted above, it could be held that those subjective to preventive detention have, through their past offending, rendered themselves liable to certain intrusions in a way that those subjected to quarantine have not.

\footnotetext{
${ }^{16}$ For an example of how such an argument might go, see Ashworth and Zedner's discussion in this volume of how the case in favour of minimising the harmfulness of quarantine might carry over to the case of preventive detention. For an argument that preventively detained individuals ought to be offered treatment, see Slobogin (2011: 1139-40).
} 


\section{References}

Ashworth, A and Zedner, L (this volume) 'Some Dilemmas of Indeterminate Sentencing: Risk and Uncertainty, Dignity and Hope', in J de Keijser, JV Roberts, and J Ryberg (eds) Risk and Sentencing: Ethical and Empirical Perspectives (Oxford, Hart Publishing).

Bagger, JP, Zindrou D, and Taylor KM (2004) 'Postoperative Infection with MeticillinResistant Staphylococcus Aureus and Socioeconomic Background' 363 Lancet 706.

Caruso, GD (2016) 'Free Will Skepticism and Criminal Behavior: A Public HealthQuarantine Model' 32 Southwest Philosophy Review 25.

Childress, JF, Faden, RR, Gaare, RD, Gostin, LO, Kahn, J, Bonnie, RJ, Kass, NE, Mastroianni, AC, Moreno, JD, and Nieburg, P (2002) 'Public Health Ethics: Mapping the Terrain' 30 The Journal of Law, Medicine \& Ethics 170.

Corrado, ML (1996a) 'Punishment and the Wild Beast of Prey: The Problem of Preventive Detention' 86 Journal of Criminal Law and Criminology 778.

- (1996b) 'Punishment, Quarantine, and Preventive Detention' 15 Criminal Justice Ethics 3.

Douglas, T (2014) 'The dual-use problem, scientific isolationism and the division of moral labour' 32 Monash Bioethics Review 86.

Duff, RA (2007) Answering for Crime: Responsibility and Liability in the Criminal Law (Oxford, Hart Publishing).

European Centre for Disease Prevention and Control (ECDC)/World Health Organization Regional Office for Europe (2013) Tuberculosis Surveillance and Monitoring in Europe 2013. (Stockholm: ECDC). Available from: http://www.ecdc.europa.eu/en/publications/Publications/Tuberculosis-surveillancemonitoring-2013.pdf .

Schoeman, FD (1981) 'On Incapacitating the Dangerous', in H Gross and A von Hirsch (eds.) Sentencing (Oxford, Oxford University Press).

Gavaghan, C, Snelling, J and McMillan, J (2014) Better and Better and Better? A Legal and Ethical Analysis of Preventive Detention in New Zealand: Report for the New Zealand Law Foundation (Dunedin, University of Otago).

Gostin, LO (2001) Public Health Law: Power, Duty, Restraint (London, University of California Press).

Hannah-Moffat, K and Struthers Montford, K (this volume) 'Unpacking Sentencing Algorithms Risk, Racial Accountability, and Data Harms', in J de Keijser, JV Roberts, and J Ryberg (eds) Risk and Sentencing: Ethical and Empirical Perspectives (Oxford, Hart Publishing).

Harcourt, BE (2012) 'Punitive Preventive Justice: A Critique' Coase-Sandor Working Paper Series in Law and Economics 599.

Hart, HLA (1968) Punishment and Responsibility: Essays in the Philosophy of Law (Oxford, Oxford University Press).

Hoskins, Z (2013) 'Punishment, Contempt, and the Prospect of Moral Reform' 32 Criminal Justice Ethics, 1.

Hrivniaková, L, Sláčiková, M, and Kolcunová, S (2009) 'Hepatitis An Outbreak in a Roma Village in Eastern Slovakia' Eurosurveillance 14.

Husak, D (this volume), 'Why Legal Philosophers, Including Retributivists, Should Be Less Resistant to Risk-Based Sentencing', in J de Keijser, JV Roberts, and J Ryberg (eds) Risk and Sentencing: Ethical and Empirical Perspectives (Oxford, Hart Publishing). 
Kitai-Sangero, R (2009) 'The Limits of Preventive Detention' 40 McGeorge Law Review 903.

Klinkenberg, E, Manissero, D, Semenza, JC, and Verver, S (2009) 'Migrant Tuberculosis Screening in the EU/EEA: Yield, Coverage and Limitations' 34 European Respiratory Journal 1180.

McCloskey, HJ (1972) 'A Non-Utilitarian Approach to Punishment' in G Ezorsky (ed) Philosophical Perspectives on Punishment (Albany, University of New York Press).

Meyerson, D (2009) 'Risks, Rights, Statistics and Compulsory Measures' 31 Sydney Law Review 507.

Morse, SJ (2011) 'Protecting Liberty and Autonomy: Desert/Disease Jurisprudence' 48 San Diego Law Review 1077.

Murphy, LB (1999) 'Institutions and the Demands of Justice' 27 Philosophy \& Public Affairs 251.

Nagel, T (1995) Equality and Partiality (New York, Oxford University Press).

Pereboom, D (2014) Free Will, Agency, and Meaning in Life (Oxford, Oxford University Press).

Rawls, J (1993) Political Liberalism (New York, Columbia University Press).

Scheffler, S (2005) 'Egalitarian Liberalism as Moral Pluralism' 79 Aristotelian Society Supplementary Volume 229.

Semenza, JC, Giesecke, J (2008) 'Intervening to Reduce Inequalities in Infections in Europe' 98 American Journal of Public Health 787.

Sidhu, DS (2015) 'Moneyball Sentencing' 671 Boston College Law Review 672.

Silver, E and Miller, LL (2002) 'A Cautionary Note on the Use of Actuarial Risk Assessment Tools for Social Control' 48 Crime \& Delinquency 138.

Slobogin, C (2011) 'Prevention as the Primary Goal of Sentencing: The Modern Case for Indeterminate Dispositions in Criminal Cases’ 48 San Diego Law Review 1127.

Smilansky, S (1994) 'The Time to Punish' 54 Analysis 50.

- (2017) 'Pereboom on Punishment: Funishment, Innocence, Motivation, and Other Difficulties' 11 Criminal Law and Philosophy 591.

Twisselmann, B (2000) 'Risk Factors for Meningococcal Disease in Children in the Czech Republic' 4 Eurosurveillance.

van Brakel, WH (2006) 'Measuring Health-Related Stigma-A Literature Review' Psychology, 11 Health \& Medicine 307

van Ginneken, EFJC (this volume) 'The Use of Risk Assessment in Sentencing', in J de Keijser, JV Roberts, and J Ryberg (eds) Risk and Sentencing: Ethical and Empirical Perspectives (Oxford, Hart Publishing).

von Hirsch, A (1972) 'Prediction of Criminal Conduct and Preventive Confinement of Convicted Persons' 21 Buffalo Law Review 717.

_ (1992) 'Proportionality in the Philosophy of Punishment' 16 Crime and Justice 55.

Whittle, HJ, Palar, K, Ranadive, NA, Turan, JM, Kushel, M and Weiser, SD (2017) 'The Land of the Sick and the Land of the Healthy": Disability, Bureaucracy, and Stigma Among People Living with Poverty and Chronic Illness in the United States' 190 Social Science \& Medicine 181.

Williams, CJ, Willocks, LJ, Lake, IR, Hunter, PR (2004) 'Geographic Correlation Between Deprivation and Risk of Meningococcal Disease: An Ecological Study' 4 BMC Public Health.

Zedner, L (2010) 'Pre-crime and Pre-punishment: A Health Warning' 81 Criminal Justice Matters 24. 